\title{
We Are All Getting Sick. Who Will Take Care of Who?
}

\author{
Julio Cesar Andre, MD, PhD* \\ Researcher in Center for the Study and Development of Health Education - CEDES, Brazil
}

Keywords:Human Sciences; health sciences education; health staff; quality of life; work ability, worker's health

In the context of contemporary health sciences education, one expects that the practicing conduct of health professionals presents positive attitudes towards the patient. However, what can be observed is a growing decline in humanistic values on the part of future health professionals, associated with an increased loss of idealism and empathy, increased skepticism, loss of feelings of accomplishment and satisfaction with the professional choice. One expects the future professional to follow socially accepted patterns guided by ethics, and favorable to the development of the professional-patient relationship, thus contributing to a good interposition in the health-disease process [1]. The technical domain is crucial to save lives but insufficient to maintain quality of life and avoid illness. The challenge, therefore, lies in an adequate dosage between technical education and the exercise of humanized practice, context where the Social and Human Sciences enter.

The patient of the future is an empowered one, interested in shared decision making; one who knows that even after the careful monitoring of their vital signs they will still have family needs and will most likely want to be cared for by a compassionate professional; they will seek the wise advice of an experienced counselor and of those who know them in their natural context. They will desire an attentive ear from someone who respects their dignity and privacy. They will require simple interpretation of isolated data so they can make sense in their lives, seek explanations as well as meaning, and sometimes require only a silent witness to their suffering. They will need to know that their health care professional actually cares [2].Scholars acknowledge the university's responsibility in humanistic education since such institution shapes the professional, thus recognizing its role; scholars hope that universities will provide more than just technical-scientific and rational content, but humanistic modeling, since they believe the university can still shape the health professional while in grad school, even if they do not yet present sufficient ethical and humanistic qualities for their professional practice. Thus, it is clear the important role university and professors have in reinforcing humanistic practices in health professions [3].

We are experiencing a unique moral and values crisis that affects the entire human species, and as the human beings that they are (or should be), health professionals do not escape it. Students, regardless of field, should (yes, in the conditional tense), assimilate the ethics and human aspect of their professional practice from the mentors, from basic to vocational areas, they encounter during their training period (professors, preceptors, tutors, residents and even family and professional friends). Why "should"? I turn again to the question of the moral and values crisis.

Parallel to the moral and value crisis, or as its consequence, health professionals are getting sick. Among the professional categories, health workers have been constantly appointed as a risk group for physical and mental illnesses. In their daily work, health professionals are faced with people or groups in complex and extreme situations, e.g., sexual violence, starvation, abandonment, misery, among others, which can generate anguish and contribute to the emergence of functional diseases, including the Burnout syndrome, a combination of low sense of personal fulfillment, feelings of depersonalization and loss of work enthusiasm. Physical and mental illnesses are common in professions involving frequent interactions with people, the "object" of work for health professionals. This high risk for illness development probably relates to long working hours, high levels of stress, sleep deprivation and lack of leisure time associated with graduate training and continued education. 
The negative effects that health professional's physical wear have on quality of patient care, conduct and professional attitudes, professional errors and others is a moot point.

This type of illness already begins during graduation because of representations of hierarchy and oppression characterized by the perpetuation of the hidden curriculum, during and after graduation, are numerically more expressive, with emphasis on the relationship among the students due to the vertical and violent conjuncture that allows such relations manifest as hazing and the oppressive presence of "intimidating environments", among others. The perpetuation of the hidden curriculum is extremely harmful to the formation of professional identity [4]. Admitting and calling people's attention to its existence may be the first and most important step to promote management measures and initiatives are already emerging in this direction [5].

There is a reciprocal relationship between the formation of a desirable professional identity and the development and strengthening of professionalism, and the formation of this desirable professional identity cannot happen adequately in the presence of elements of hierarchy and oppression among students, in the learning process, in student institutions, between student and teacher, thus compromising the development and strengthening of professionalism, whose absence is the "biggest blow ${ }^{\text {ee }}$ of the honorable medical profession, which is about to be reduced to a business [6].

The health-illness duality experienced incessantly by human beings over the course of life constitutes a complex and dynamic phenomenon that expresses the interaction of multiple processes, among which work is one of the determinants. While subjects recognize the importance of work to guarantee material and subjective conditions favorable to health, they highlight its effects on the physical and psychic wear of workers, by boosting stress, absence of healthy habits, hypertension, sleep disorders, musculoskeletal and gastrointestinal disorders, and somatic manifestations of minor mental disorders. A paradigm permeated by contradictions because while health professionals participate in producing individual and collective health, this activity can have negative effects on their own health, whose impacts are the frailty of care provided to the population and the interference in their families' quality of life.

We must face this reality to enhance the professionals' health and, consequently, the quality of user care, since health workers' illness is strongly related to the existing health care model in society, increasing the risk of having your mental health gradually impaired. The overall quality of life of health professionals is influenced by physical and psycho-emotional factors that involve the complex work relationships to which they are exposed during the development of their care and management practices; this shows the centrality that work occupies in their lives and how important it is in the process of personal and professional self-realization. Resilience contributes to the readiness of health professionals in providing care. A culture of reliable educational learning promotes resilience, so that educators of health professions can support the development of resilience by their students, future health professionals.

Considering that organizational commitment is associated with job satisfaction and the professional work environment, organizational and unit managers can increase employee participation in decision making and give them the opportunity to achieve their value, in other words, give a stronger hand to health professionals, providing them with access to resources and creating new perspectives on strategies to increase their quality of life, organizational commitment and work satisfaction. The improvement of communication and cooperation, the establishment of participatory management and the improvement of the strengths / training of workers will also be complementary in maintaining a healthy organizational structure. This needs to be known and considered by health managers, so we do not reach a seemingly inevitable point: we are all getting sick. Who will take care of who?

\section{REFERENCES}

[1] Andrade SC, Deus JA, Barbosa ECH, Trindade EMV (2011) Evaluation of the Development of Humanistic Attitudes in Undergraduate Medical Studies. RBEM 35(4): 517-525

[2] Yaphe J (2016) the future of the patient and the patient of the future. Rev Port Med GeralFam 32:370-1

[3] André JC, Lima ARA, Brienze SLA, Werneck AL, Afonso DH, Fucuta PS (2019) Perception of Medical Intern Students about the Gaps in Their Medical Training Related To Human Skills and Competences and the Role of Teachers and Preceptors. Int J Latest Res Humanities Social Sci 02(07): 17-24

[4] Barbosa JLA, André JC, Santos ER, Santos LL, Santos Jr. R, Brienze SLA, Lima ARA (2019) Hierarchy and Oppression in Medical School: Perception of Initial Grade Academics and its Repercussion on Professional Identity Formation. Int J Arts Social Sci 2(6): 66-78 
[5] Yazdani S, Momeni S, Afshar L, Abdolmaleki MR (2019) A comprehensive model of hidden curriculum management in medical education. J Advances Med Education \& Professionalism, 7(3): 123-130.

[6] Forouzadeh M, Kiani M, Bazmi S (2018) Professionalism and its role in the formation of medical professional identity. Med J Islamic Republic Iran, 32: 130.

\section{AUTHORS' BIOGRAPHY}

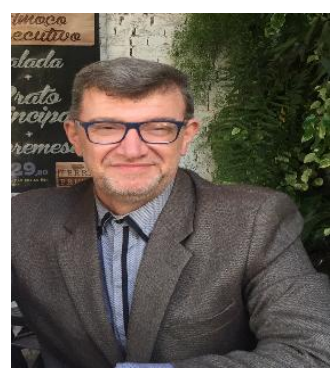

Júlio César André, MD, PhD,MD (Faculty of Medicine of São José do Rio Preto - FAMERP), PhD Morphology - Cell Biology (Faculty of Medicine of Ribeirão Preto / USP), specialist in Institutional Evaluation (University of Brasília - UNB), fellow Foundation for Advancement of International Medical Education and Research - FAIMER BRASIL 2015, specialist in Teacher Development for Educators of the Health Professions by the Federal University of Ceará. Researcher at the Center for Studies and Development of Health Education at FAMERP (CEDES - FAMERP), and his research areas are: educational environment, mixed teaching-learning methods, learning by people, health student mental, social sciences interface with medicine and spirituality and medicine.

Citation:JúlioCésar André. "We Are All Getting Sick. Who Will Take Care of Who?" International Journal of Humanities Social Sciences and Education (IJHSSE), vol 7, no. 4, 2020, pp. 70-72. doi: http://dx.doi.org/10.20431/2349-0381.0704008.

Copyright:@ 2020 Authors. This is an open-access article distributed under the terms of the Creative Commons Attribution License, which permits unrestricted use, distribution, and reproduction in any medium, provided the original author and source are credited. 